Article

\title{
Fabrication of Microfiber Patterns with Ivy Shoot-Like Geometries Using Improved Electrospinning
}

\author{
Young Hun Jeong ${ }^{1, *}$ and Jongwan Lee ${ }^{2}$ \\ 1 School of Mechanical Engineering, Kyungpook National University, 80 Daehakro, Bukgu, \\ Daegu 41566, Korea \\ 2 Department of Mechanical Engineering, Ulsan National Institute of Science and Technology (UNIST), \\ 50 UNIST-gil, Eonyang-eup, Ulsan 44919, Korea; jwlee@unist.ac.kr \\ * Correspondence: yhjeong@knu.ac.kr; Tel.: +82-53-950-5577
}

Academic Editors: Nicole Zander and Hong Dong

Received: 22 December 2015; Accepted: 27 January 2016; Published: 1 April 2016

\begin{abstract}
Fibers and fibrous structures are used extensively in various fields due to their many advantages. Microfibers, as well as nanofibers, are considered to be some of the most valuable forms of advanced materials. Accordingly, various methods for fabricating microfibers have been developed. Electrospinning is a useful fabrication method for continuous polymeric nano- and microfibers with attractive merits. However, this technique has limitations in its ability to control the geometry of fibrous structures. Herein, advanced electrospinning with direct-writing functionality was used to fabricate microfiber patterns with ivy shoot-like geometries after experimentally investigating the effects of the process conditions on the fiber formation. The surface properties of the fibers were also modified by introducing nanoscale pores through the use of higher levels of humidity during the fabrication process.
\end{abstract}

Keywords: electrospinning; microfibers; nanofibers; direct-writing; ivy shoot-like pattern; fractals

\section{Introduction}

Various fibers and fibrous structures are attracting significant attention in many different fields, such as cosmetics, clothing, electronics, environmental, chemical, and nano- and bioengineering [1]. Well-known nanofibers are a promising advanced material, but microfibers, a fiber form having a different order of scale, are also used widely in various areas, such as tissue engineering [2-4], drug delivery [5,6], filtration [7,8], and composite reinforcement [9], owing to their numerous advantages, including high porosity, large pore size, large surface area-to-volume ratio, high flexibility, and similarity in structural form with the human body's extracellular matrices. In particular, microfibers have yielded better quality results when compared to nanofibers; e.g., microfiber and multilayered scaffolds have improved quality and perform better in terms of initial cell attachments and cell infiltration processes compared with nanofibrous scaffolds in tissue engineering [3].

To date, various methods have been developed to fabricate microfibers. In general, spinning methods such as wet-, dry-, and gel-spinning processes have been used successfully to fabricate microfibers for various applications [10-14]. Various types of microfluidic chips have also been used as nozzles for extrusion with versatile functionalization, such as Janus structures with multiple materials and bubbling $[2,4,15,16]$. In particular, the electrohydrodynamic hot-jet plotting process has been introduced to microfiber fabrication, providing better controllability and fiber diameters as small as $5 \mu \mathrm{m}$ [17]. A slit die extrusion and heat stretching process for fabricating microfibers has also been demonstrated [18]. 
Electrospinning is one of the most attractive methods for fabricating continuous polymeric fibers with diameters ranging from micro- to nanometer scales because this technique does not pose serious limitations on the material selection and requires simple fabrication equipment with relatively easy process operations [1]. Therefore, various fibers and fibrous structures with different sizes, geometries, and materials have been fabricated using electrospinning and applied to a variety of fields. Especially, Pham et al. reported that the diameter of electrospun microfibers could be accurately controlled through the proper selection of process parameters, such as electric field, concentration, and flow rate [3]. Fridrikh et al. identified the relationship between fiber diameter, surface tension, flow rate, and electric current in the jet [19]. McKee et al. investigated the effects of concentration/viscosity on electrospun fiber diameter [20]. However, the conventional electrospinning process has limitations in terms of the geometric control of fibrous structures owing to the whipping motion that results from the bending instability of the electrospinning jet [21]. In this regard, conventional electrospinning is only suitable for fabricating randomly deposited nonwoven fibrous meshes, even though uniaxially aligned fibrous mats can be fabricated using electrospinning with a drum collector [22]. Many approaches have been tried to address this problem and obtain fibrous structures having regular shapes [23-28].

In the current study, microfibrous patterns with ivy shoot-like geometries were fabricated using an improved electrospinning process, known as direct-write electrospinning (DWES), which was developed in our previous study [29]. Since DWES improves the geometric regularity of electrospun fibers in a controllable manner, it was used to fabricate electropsun microfiber patterns to overcome their geometric control limitation. The effects of the experimental conditions, such as flow rate, scan speed, and humidity, on the microfiber formation were investigated using Euclidean and fractal analyses. As a result, we demonstrated that controllable microfiber patterns could be fabricated using the proposed electrospinning process, yielding complex and random ivy shoot-like shapes in the microfiber patterns. In addition, the surface properties could be modified by using higher levels of humidity in the fabrication process.

\section{Results and Discussion}

\subsection{Influence of the Solution Flow Rate on the Microfibers}

Polymeric fibers were electrospun under various solution flow rate conditions because this parameter was considered to be one of the dominant factors that influence the electrospun microfiber diameter [30]. In the experiments, the fabricated pattern had a lattice shape with a grid size of $500 \mu \mathrm{m}$, and the flow rates of the polycaprolactone (PCL) solution from the nozzle were 0.1, $0.3,0.6$ and $0.8 \mathrm{~mL} / \mathrm{h}$. Other experimental conditions were kept nearly constant, as indicated in Table 1. The tip-to-collector distance (TCD) and voltage for electrospinning were $60.0 \mathrm{~mm}$ and $21-24 \mathrm{kV}$, respectively.

Table 1. Experimental conditions for fabricating a fibrous lattice pattern under various flow rate conditions.

\begin{tabular}{cc}
\hline Parameter (Units) & Value \\
\hline Polymer-solvent $($ concentration, wt $\%)$ & PCL-chloroform $(8.8$ wt $\%)$ \\
Temperature $\left({ }^{\circ} \mathrm{C}\right)$ & $21-22$ \\
Relative humidity $(\%)$ & $55-58$ \\
Voltage $(\mathrm{kV})$ & $21-24$ \\
Tip-to-collector distance $(\mathrm{mm})$ & 60.0 \\
Solution flow rate $(\mathrm{mL} / \mathrm{h})$ & $0.1,0.3,0.6$ and 0.8 \\
Scan speed of collector $(\mathrm{mm} / \mathrm{s})$ & 25.0 \\
\hline
\end{tabular}

Figure 1 shows the fibrous lattice patterns fabricated under various flow rates, and their fiber diameter distributions. The fibrous pattern fabricated with a flow rate of $0.1 \mathrm{~mL} / \mathrm{h}$ is depicted in Figure 1a,b. It contained many fibers with diameters ranging from $150 \mathrm{~nm}$ to $5 \mu \mathrm{m}$. However, although plenty of microfibers are shown in Figure $1 b$, the nanometer-scale fibers still dominated the pattern. 
A well-defined lattice pattern was obtained under these conditions. The most common fiber diameter was $425 \mathrm{~nm}$, as depicted in Figure 1c.
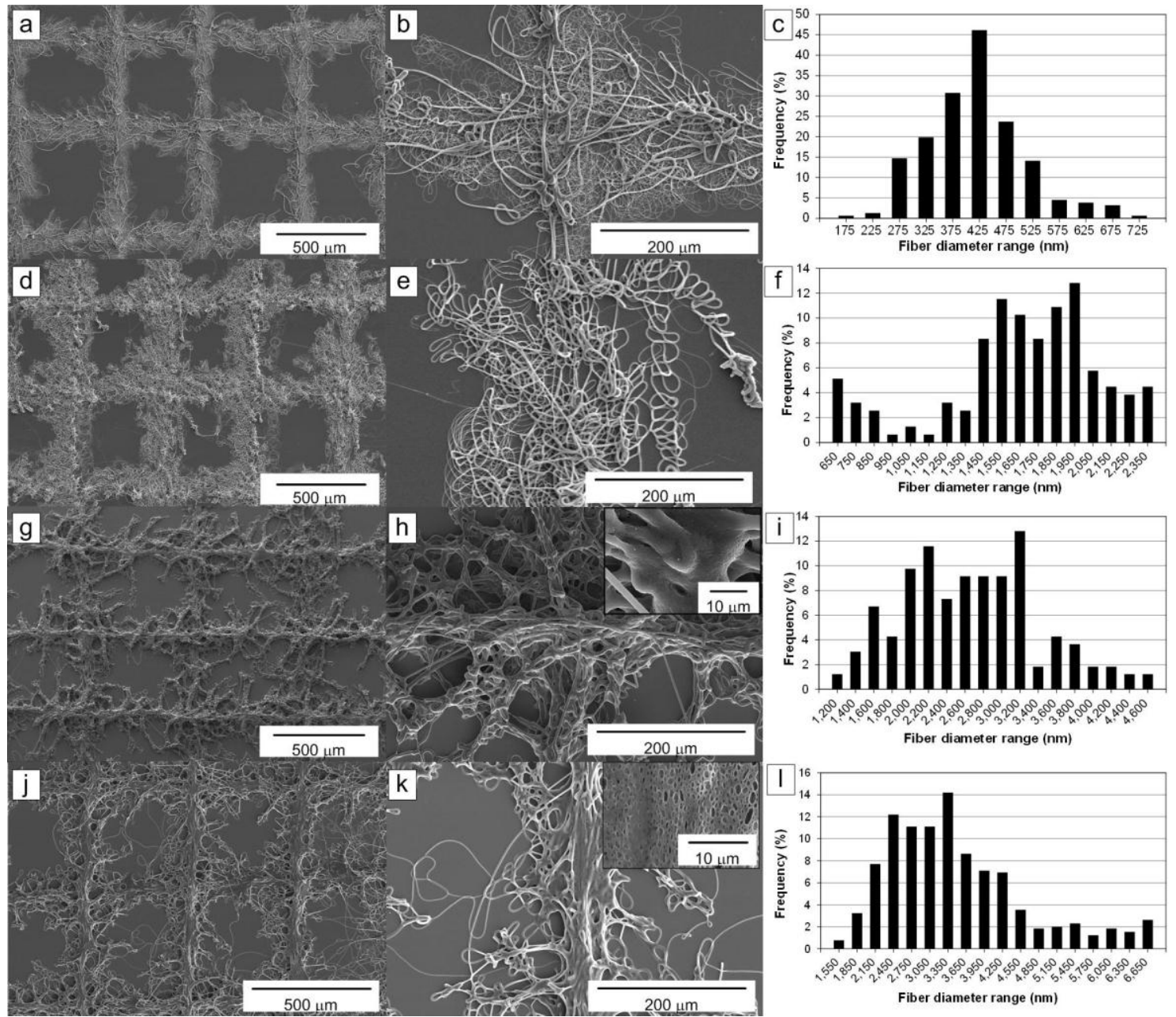

Figure 1. Scanning electron microscopy (SEM) images and fiber diameter distributions of the nano- and microfibrous lattice patterns fabricated with various solution flow rates: $(\mathbf{a}-\mathbf{c}) 0.1 \mathrm{~mL} / \mathrm{h} ;(\mathbf{d}-\mathbf{f}) 0.3 \mathrm{~mL} / \mathrm{h}$; $(\mathbf{g}-\mathbf{i}) 0.6 \mathrm{~mL} / \mathrm{h}$; and $(\mathbf{j}-\mathbf{1}) 0.8 \mathrm{~mL} / \mathrm{h}$.

Figure $1 \mathrm{~d}-\mathrm{f}$ show the pattern and fiber diameter distribution obtained using a flow rate of $0.3 \mathrm{~mL} / \mathrm{h}$. The fibrous line pattern width of the lattice pattern increased because of the higher flow rate, and most of the fibers had microscale diameters. The most common fiber diameter was $2 \mu \mathrm{m}$, and the minimum diameter was $600 \mathrm{~nm}$. The pattern still exhibited a regular lattice shape. Thus, the higher flow rate provided larger-diameter fibers.

The fiber diameter continued to increase with the flow rate. A unique morphology of the fibrous pattern was observed at a flow rate greater than $0.6 \mathrm{~mL} / \mathrm{h}$. Figure $1 \mathrm{~g}$, h show the lattice pattern obtained at a flow rate of $0.6 \mathrm{~mL} / \mathrm{h}$. In Figure $1 \mathrm{~g}$, the pattern had a unique geometry that looked like ivy shoots on a wall. The stems of the ivy shoot-like pattern (central lines) still maintained the lattice shape. However, tendril-like microfibers stretched radially from the stem lines and caused the pattern to resemble ivy shoots. The fibers had larger diameters and were fused together to create the complex morphology shown in Figure 1h, likely because a significant amount of the solvent remained in the electrospun fibers after they reached the collector plate. Therefore, the pattern had better interconnectivity among fibers compared with Figure 1b,e. Also, the width of the line pattern became narrower even though the solution flow rate was higher, and a few pores were exposed on 
the surface of the fibers due to incomplete evaporation of solvent. As shown in Figure 1i, the most common fiber diameter was between 2.2 and $3.2 \mu \mathrm{m}$.

The fiber interconnectivity continued to improve when the solution flow rate was increased to $0.8 \mathrm{~mL} / \mathrm{h}$ due to a higher degree of fiber fusion, as shown in Figure $1 \mathrm{j}, \mathrm{k}$. However, the ivy shoot-like geometric features became weaker, as depicted in Figure 1k. As expected, the porosity of the fiber surfaces increased significantly. From Figure 11, the most common microfiber diameter was $3.35 \mu \mathrm{m}$.

From the results shown in Figure 1, the fabricated nano- and microfibrous patterns had well-defined lattice shapes with various line patterns, depending on the solution flow rate used. Especially, it could be seen that the clearest ivy shoot pattern could be obtained at a flow rate of $0.6 \mathrm{~mL} / \mathrm{h}$, as shown in Figure $1 \mathrm{~g}$. However, at flow rates greater than $0.9 \mathrm{~mL} / \mathrm{h}$, it was difficult to obtain the ivy shoot pattern from the electrospun fibers.

The relationship between the solution flow rate and the fiber diameter of the fabricated lattice patterns shown in Figure 1 was obtained via statistical analysis. As illustrated in Figure 2, the average fiber diameter of the fabricated patterns increased with the solution flow rate. Thus, the average diameter of the electrospun fibers could be controlled by modifying the solution flow rate. However, the higher flow rates resulted in larger standard deviations among fiber diameters.

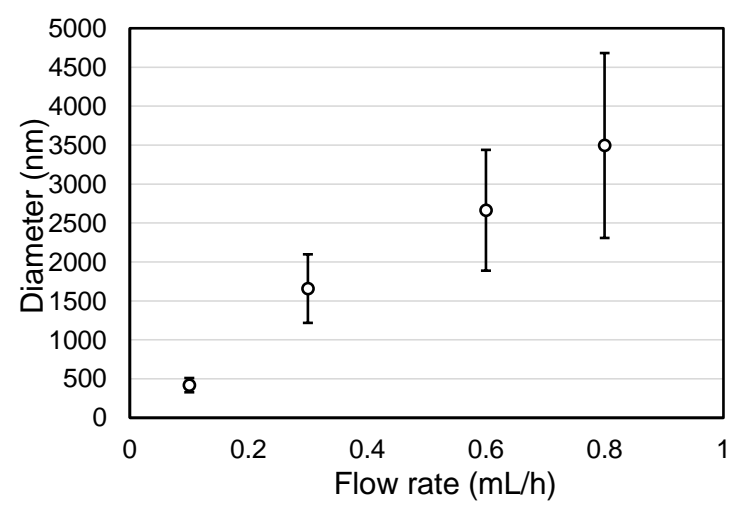

Figure 2. Relationship between solution flow rate and fiber diameter.

\subsection{Influence of the Scan Speed of the Collector}

In the experiments described in the previous section, we observed that the lattice patterns consistently possessed ivy shoot-like geometries when the solution flow rate was between 0.6 and $0.8 \mathrm{~mL} / \mathrm{h}$. Next, we modified the scan speed of the collector to adjust the degree of complexity of the ivy shoot-like geometries in the microfibrous patterns, because extending the length of time that the collector remained at one point could increase the possibility for a tendril to form. Thus, parallel-line patterns were fabricated using various collector scan speeds from 10 to $450 \mathrm{~mm} / \mathrm{s}$, as shown in Figure 3 . The other conditions were fixed as listed in Table 2. The scan path used to fabricate the parallel-line pattern had a pitch of $500 \mu \mathrm{m}$ at all scan speeds except for $450 \mathrm{~mm} / \mathrm{s}$, for which the pitch was $50 \mu \mathrm{m}$.

Table 2. Experimental conditions for fabricating parallel-line patterns at various scan speeds.

\begin{tabular}{cc}
\hline Parameter (Units) & Value \\
\hline Polymer-solvent (concentration, wt \%) & PCL-chloroform $(8.8$ wt \%) \\
Temperature $\left({ }^{\circ} \mathrm{C}\right)$ & $20-21$ \\
Relative humidity $(\%)$ & $56-58$ \\
Voltage $(\mathrm{kV})$ & 21 \\
Tip-to-collector distance $(\mathrm{mm})$ & 60.0 \\
Solution flow rate $(\mathrm{mL} / \mathrm{h})$ & 0.6 \\
Scan speed of collector $(\mathrm{mm} / \mathrm{s})$ & $10-450$ \\
\hline
\end{tabular}




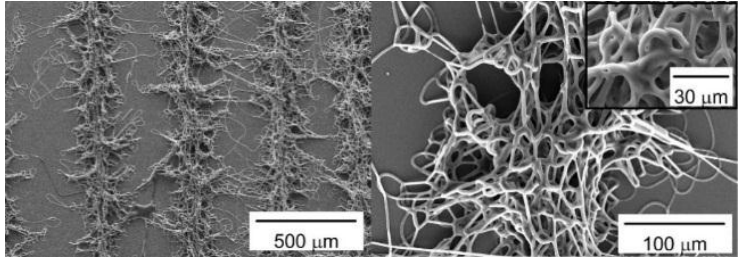

(a)

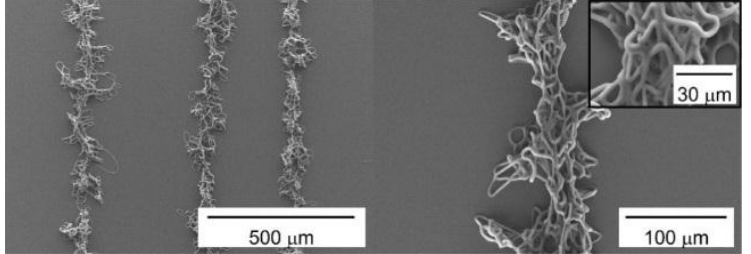

(c)

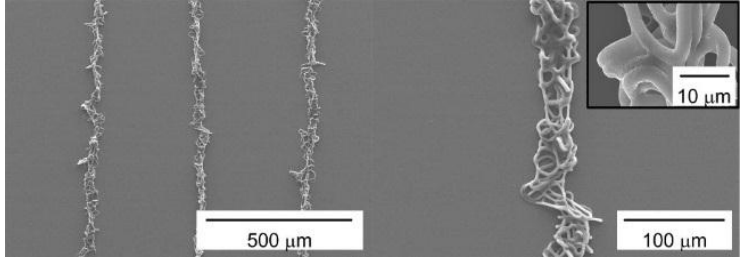

(e)

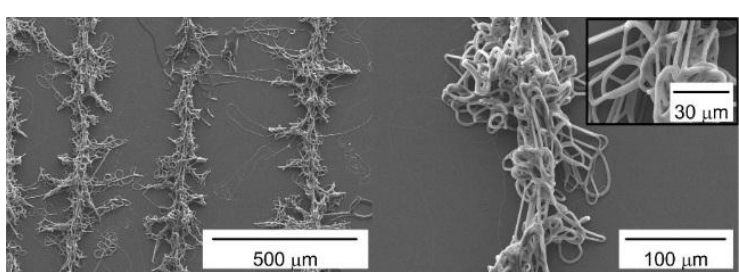

(b)

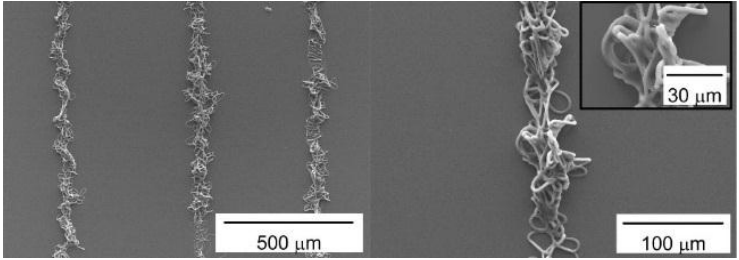

(d)

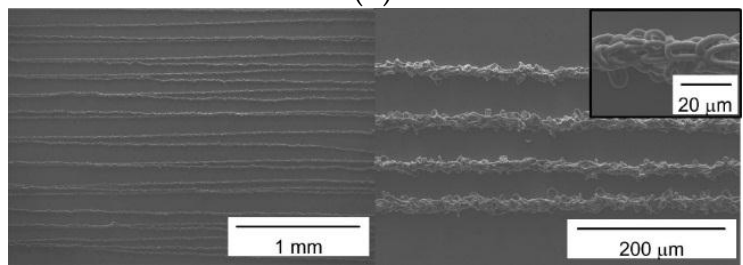

(f)

Figure 3. Influence of the scan speed of the collector on the shape morphology of the fractal geometric microfibrous patterns: SEM images of the fabricated microfibrous patterns at scan speeds of (a) 10; (b) 25; (c) 50; (d) 75; (e) 150; and (f) $450 \mathrm{~mm} / \mathrm{s}$. The scan path distance of fabricated microfibrous patterns was (a-e) $500 \mu \mathrm{m}$ and (f) $50 \mu \mathrm{m}$.

Figure 3a shows the parallel-line pattern fabricated at a scan speed of $10 \mathrm{~mm} / \mathrm{s}$. The central lines corresponding to the stem in an ivy shoot followed the scan path well with a regular pitch. Moreover, the pattern clearly showed complex tendril formation. The fabricated microfibrous patterns obtained at scan speeds of 20,50 and $75 \mathrm{~mm} / \mathrm{s}$ are presented in Figure 3b-d, respectively. The formation of tendrils in the microfibrous line patterns decreased gradually as the scan speed increased. At the same time, the width of the line patterns narrowed. In Figure 3e, which shows the pattern fabricated at a scan speed of $150 \mathrm{~mm} / \mathrm{s}$, it is difficult to identify any clear tendrils along the line patterns. Moreover, we obtained a straight-line pattern without tendrils at a scan speed of $450 \mathrm{~mm} / \mathrm{s}$, as shown in Figure $3 \mathrm{f}$, with highly arranged entanglements. Thus, the degree of complexity obtained using the proposed electrospinning process could be controlled via changes in the scan speed. The inferred explanation for this result is that the longer durations spent by the collector at a given point due to the slower scan speeds introduced a greater possibility for the microfibrous pattern to extend tendrils (fingers).

The effect of the scan speed on the tendril formation in the fabricated microfibrous patterns was evaluated by the well-defined fractal dimension, which could describe complexity or area filling of chaotic geometries in nature [31,32]. We calculated fractal dimensions of the patterns for various scan speed conditions. Figure 4 shows fractal dimension of line patterns fabricated under the conditions mentioned in Table 2 and Figure 3. The fractal dimension of the line pattern fabricated at a scan speed of $10 \mathrm{~mm} / \mathrm{s}$ was about 1.612 with a standard deviation of about 0.024 . The dimension decreased as the scan speed increased, thus it became down to $1.205 \pm 0.019$ when the scan speed was $150 \mathrm{~mm} / \mathrm{s}$. Especially, the fractal dimension of the pattern fabricated at a scan speed of $450 \mathrm{~mm} / \mathrm{s}$ was $1.059 \pm 0.011$, which was close to 1.0, corresponding to the typical one-dimensional geometry (i.e., simple line). In this regard, it could be concluded from the figure that the fractal dimension of the microfibrous patterns at flow rate of $0.6 \mathrm{~mL} / \mathrm{h}$ ranged between 2.0 and 1.0 and the slower scan speed led the higher fractal dimension.

The characteristics of the ivy shoot-like geometries in the fabricated microfibrous patterns were analyzed to more clearly identify the effect of scan speed, as shown in Figure 5. First, we established a 
simple measure of the degree of complexity of a fractal geometry in the microfibrous line patterns. The shapes in Figure 5a, which presents a typical fractal geometry in a fabricated microfibrous pattern, resemble ivy shoots on a wall, and thus the geometric characteristics were defined according to the geometry of ivy shoots. The line patterns of microfibers with fractal geometries were therefore identified as shoots in this study. The main line patterns corresponding to the scan path were identified as stems, and the branches from the stems were identified as tendrils. Therefore, a shoot consisted of a stem and many tendrils. Figure $5 \mathrm{~b}$ illustrates the relationship between the stem width and the scan speed. The width narrowed with increasing scan speed. The line width ranged between 20 and $30 \mu \mathrm{m}$ at scan speeds greater than $100 \mathrm{~mm} / \mathrm{s}$; in particular, the width could be reduced to $20 \mu \mathrm{m}$ when the scan speed was $450 \mathrm{~mm} / \mathrm{s}$. Also, the line widths tended to have larger standard deviations at lower scan speeds because the instability of the deposition increased. The effects of the scan speed on the length and number of tendrils showed trends similar to the stem width, as shown in Figure 5c,d. The tendrils extended to about $90 \mu \mathrm{m}$ on average; however, no tendrils were identified in the samples fabricated with scan speeds greater than $200 \mathrm{~mm} / \mathrm{s}$. Consequently, the complexity of the fractal geometries in a fabricated microfibrous mat, which could be characterized by the average width of the stems, and the number and average length of the tendrils, could be controlled via the scan speed.

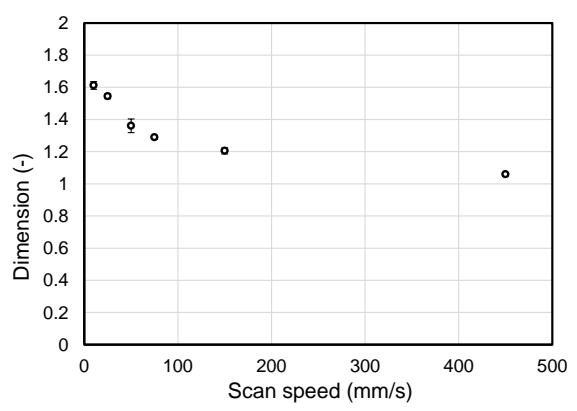

Figure 4. Influence of the scan speed of the collector on the fractal dimension of the ivy shoot-like microfibrous patterns.

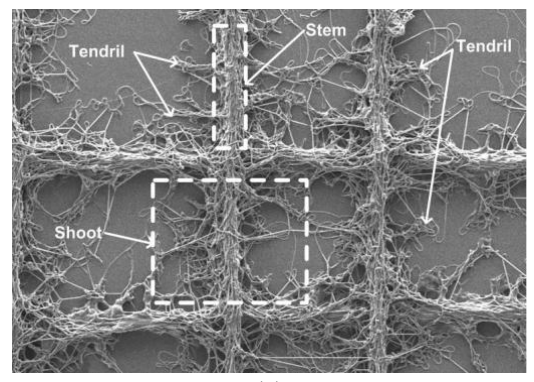

(a)

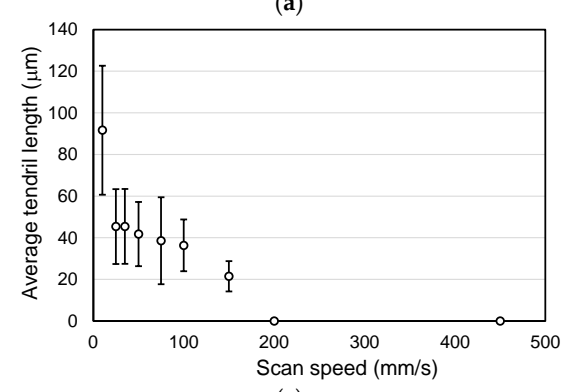

(c)

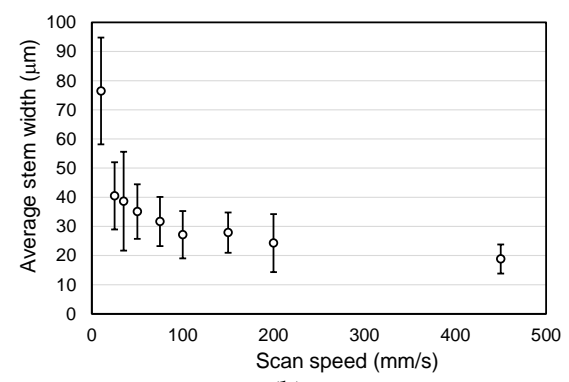

(b)

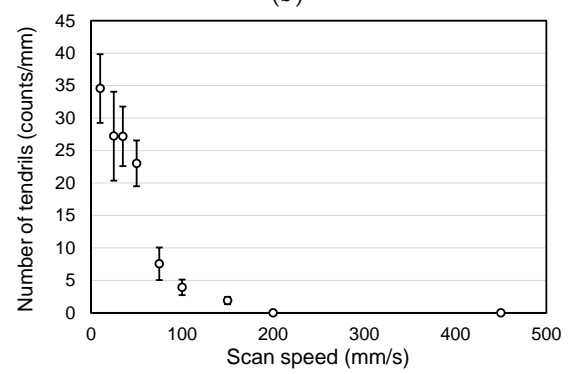

(d)

Figure 5. (a) Explanatory image showing how the fabricated fractal geometric microfibrous patterns consist of stems, tendrils, and shoots. Relationships between the scan speed of the collector and the (b) average stem width; (c) average tendril length; and (d) number of tendrils. 


\subsection{Influence of the Relative Humidity}

Porosity can be introduced to the surface of electrospun micro- or nanofibers by controlling the humidity. This is because the humidity can influence the evaporation of solvent from electrospun fibers. Nanopores introduced to microfibers can affect various surface properties. Thus, parallel-line patterns with a line pitch of $500 \mu \mathrm{m}$ were fabricated at two different levels of relative humidity, $51 \%$ and $60 \%$, which was selected from preliminary tests and the experiments mentioned at Tables 1 and 2 . The higher humidity led to more pores on the microfiber surface under the flow rate fixed at $0.6 \mathrm{~mL} / \mathrm{h}$. However, clear pores could not be observed at humidity lower than 60 percent relative humidity ( $\mathrm{RH} \%$ ). When humidity was $60 \mathrm{RH} \%$, clear pores covering the surface could be obtained. However, the amount of electrospun fibers significantly decreased when the humidity was higher than $60 \mathrm{RH} \%$. The experimental conditions are listed in Table 3.

Table 3. Experimental conditions for fabricating microfibrous mats at different levels of relative humidity.

\begin{tabular}{cc}
\hline Parameter (Units) & Value \\
\hline Polymer-solvent $($ concentration, wt $\%)$ & PCL-chloroform $(8.8$ wt $\%)$ \\
Temperature $\left({ }^{\circ} \mathrm{C}\right)$ & $20-21$ \\
Voltage $(\mathrm{kV})$ & 21 \\
Tip-to-collector distance $(\mathrm{mm})$ & 60.0 \\
Solution flow rate $(\mathrm{mL} / \mathrm{h})$ & 0.6 \\
Scan speed of collector $(\mathrm{mm} / \mathrm{s})$ & 20 \\
Relative humidity $(\%)$ & 51 and 60 \\
\hline
\end{tabular}

All patterns exhibited fractal geometries, regardless of the relative humidity. However, the pattern fabricated at the lower humidity that had no pores on its surface (Figure $6 \mathrm{a}-\mathrm{c}$ ), unlike the pattern fabricated at higher humidity was covered by micro- and nanopores (Figure 6d-f). The diameter distribution of the pores covering the surface of the pattern shown in Figure $6 \mathrm{f}$ is given in Figure 7. Most of the pores had diameters ranging between 200 and $800 \mathrm{~nm}$, and the most common pore diameter was about $550 \mathrm{~nm}$. The average pore diameter was $599.3 \mathrm{~nm}$.

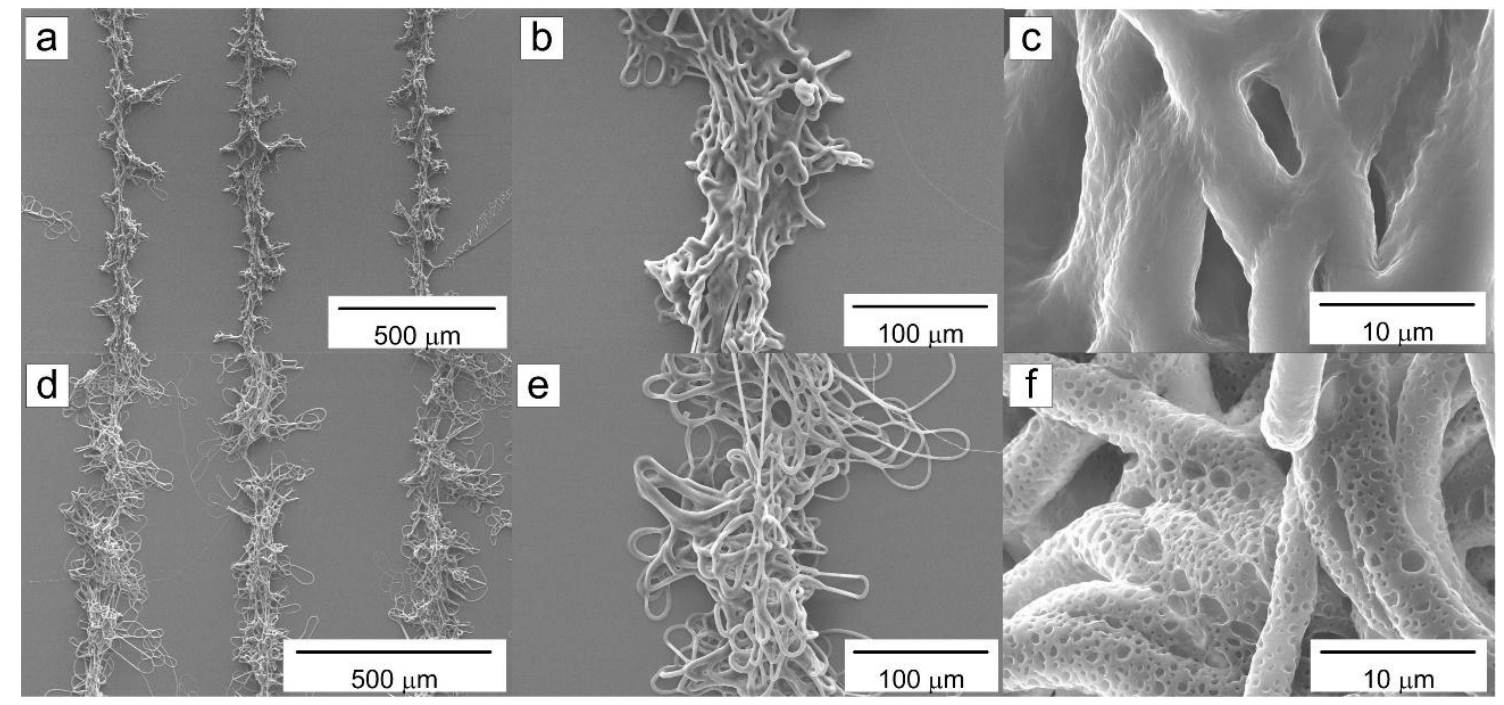

Figure 6. SEM images of fractal geometric microfibrous patterns obtained at different levels of relative humidity: (a-c) $51 \%$, and (d-f) $60 \%$. 


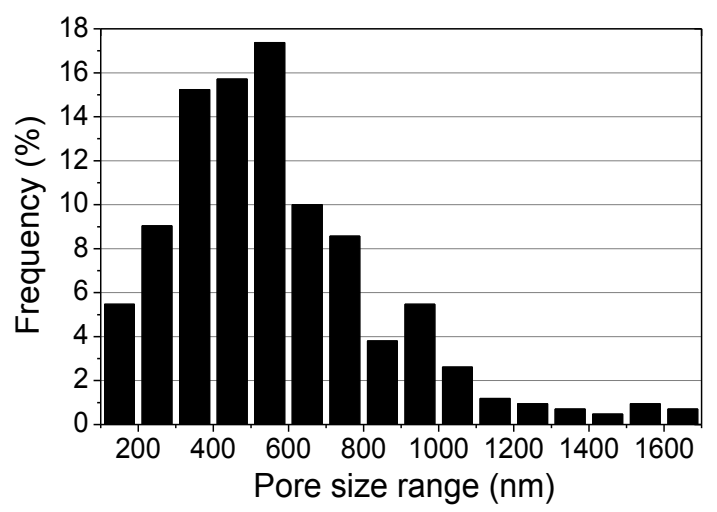

Figure 7. Pore size distribution of the fractal geometric microfibrous pattern shown in Figure $6 \mathrm{~d}-\mathrm{f}$ obtained at $60 \%$ relative humidity.

\section{Experimental Section}

The fabrication of microfiber patterns with regular geometries requires an improved electrospinning apparatus that can focus the electrospinning jet and provide a scanning motion for fiber deposition. Thus, we used a DWES experimental setup, which was developed in our previous study [29]. Figure 8a shows a schematic diagram of the DWES setup, which was based on a conventional electrospinning apparatus composed of a syringe pump, high-voltage supply, micronozzle, and conductive collector plate. However, in this study, the conductive collector plate in the conventional electrospinning setup was replaced with a sharp-pin grounded electrode and a thin borosilicate plate collector with a thickness of about $150 \mu \mathrm{m}$. Also, an aluminum-coated cylindrical electrode was introduced to enhance the performance of the electrospinning jet focusing. The borosilicate plate was given a planar motion with the help of a motorized XY stage equipped with linear servo motors, while the sharp-pin grounded electrode was fixed to ground. The tip-to-collector distance (TCD) was controlled using a vertical motorized stage, while the distance between the collector and the sharp pin was fixed at about $20 \mu \mathrm{m}$ using a manual stage. Figure $8 \mathrm{~b}$ shows the actual electrospinning setup used in this study. The electrospinning apparatus was isolated using an acrylic chamber, and thus the atmospheric conditions, such as temperature and relative humidity, could be controlled at consistent levels. The polymer used to fabricate the microfibers was a polycaprolactone with an average molecular weight ranging between 70,000 and 90,000 (PCL, 440744, Sigma-Aldrich, Co., St. Louis, MO, USA), which was dissolved in $99.5 \%$ pure chloroform (C0584, Samchun Pure Chemical Co., Ltd., Seoul, Korea) at a concentration of $8.8 \mathrm{wt} \%$ via stirring for $120 \mathrm{~min}$.

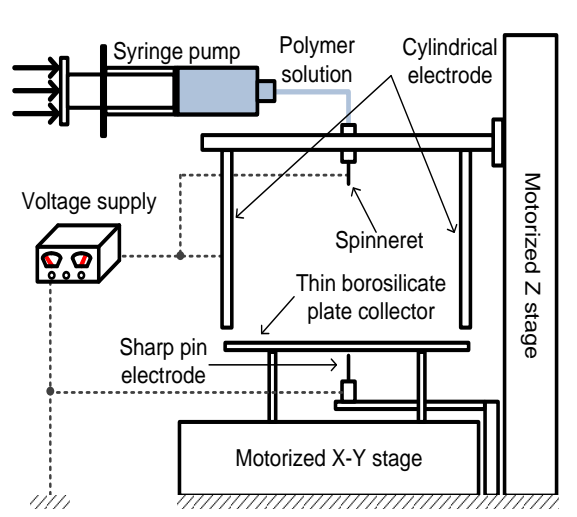

(a)

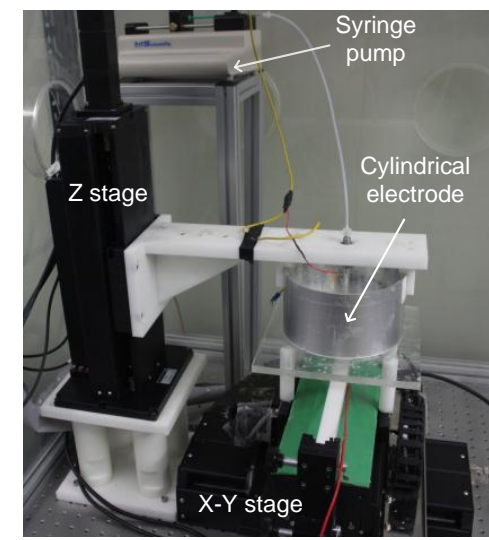

(b)

Figure 8. Electrospinning setup for fabricating microfiber patterns: (a) Schematic diagram of the direct-write electrospinning (DWES) apparatus and (b) actual DWES apparatus. 
SEM images shown in Figures 1, 3, 5 and 6 were acquired using a field-emission scanning electron microscope (S4700, Hitachi Co., Tokyo, Japan), after the fabricated samples were sputter-coated with platinum (E-1030, Hitachi Co.). The fiber diameter analyses were performed using ImageJ program (NIH). For the analysis, we used three different samples and an exemplary SEM image with a size of $120 \mu \mathrm{m} \times 160 \mu \mathrm{m}$ was selected for each sample. The number of measurements of fiber diameter for each image ranged between 155 and 648, which depended on fiber size and pattern quality. The fractal dimensions were analyzed using the Fractalyse program [33]. In the calculation of fractal dimension of the pattern at each condition, three different line pattern samples were used. Especially, the SEM image for each sample was converted to black (fibers) and white (background) image using image processing for the Fractalyse program.

\section{Conclusions}

We demonstrated that microfibrous patterns with fractal geometries that looked like ivy shoots on a wall could be successfully fabricated using an advanced electrospinning method with specific process conditions. A direct-write electrospinning method consisting of an additional cylindrical side-wall electrode, a dielectric thin collector plate with planar motion, and a sharp-pin grounded electrode, as well as a conventional electrospinning apparatus, was employed in the fabrication to introduce focusing and scanning functionalities to the electrospinning jet. As a result, fibrous patterns with regular shapes were successfully fabricated. The solution flow rate, scan speed of the collector, and relative humidity were considered as key parameters in the fabrication of the microfibrous patterns with fractal geometries. The solution flow rate directly influenced the fiber diameter; microscale fibers were obtained using flow rates greater than $0.3 \mathrm{~mL} / \mathrm{h}$. The fractal geometries were introduced to the fibrous patterns by using collector scan speeds that were less than $100 \mathrm{~mm} / \mathrm{s}$ with a flow rate that was greater than $0.6 \mathrm{~mL} / \mathrm{h}$. The scan speed strongly influenced the dimensions and complexity of the fractal geometries. Higher levels of humidity introduced nanoscale pores on the surface of the microfibers, which could offer a variety of functionalities.

The ivy shoot-like pattern presented in this study can be used in various applications related to tissue engineering, biochip application, and drug delivery. Its more-natural geometry can give cells in culture a positive effect on guidance toward more realistic engineered tissues. It can be used as a mold master for microfluidic biochip which can introduce more realistic vascular network or surface properties. Also, it would be a good drug carrier because of its area filling property, which is a well-known feature of fractal geometry.

Acknowledgments: This work was supported by the National Research Foundation of Korea (NRF) funded by the Korea government (MSIP) (NRF-2015R1A2A2A01005515).

Author Contributions: Young Hun Jeong conceived and designed the experiments, then he analyzed the experimental results and wrote the paper; Jongwan Lee performed the experiments and analyzed the experimental results.

Conflicts of Interest: The authors declare no conflict of interest.

\section{References}

1. Huang, Z.M.; Zhang, Y.Z.; Kotaki, M.; Ramakrishna, S. A review on polymer nanofibers by electrospinning and their applications in nanocomposites. Compos. Sci. Technol. 2003, 63, 2223-2253. [CrossRef]

2. Hwang, C.M.; Khademhosseini, A.; Park, Y.; Sun, K.; Lee, S.-H. Microfluidic chip-based fabrication of PLGA microfiber scaffolds for tissue engineering. Langmuir 2008, 24, 6845-6851. [PubMed]

3. Pham, Q.P.; Sharma, U.; Mikos, A.G. Electrospun poly( $\varepsilon$-caprolactone) microfiber and multilayer nanofiber/microfiber scaffolds: Characterization of scaffolds and measurement of cellular infiltration. Biomacromolecules 2006, 7, 2796-2805. [CrossRef] [PubMed]

4. Lee, K.H.; Shin, S.J.; Park, Y.; Lee, S.H. Synthesis of cell-laden alginate hollow fibers using microfluidic chips and microvascularized tissue-engineering applications. Small 2009, 5, 1264-1268. [CrossRef] [PubMed] 
5. Sill, T.J.; von Recum, H.A. Electrospinning: Applications in drug delivery and tissue engineering. Biomaterials 2008, 29, 1989-2006. [CrossRef] [PubMed]

6. Ranganath, S.H.; Wang, C.-H. Biodegradable microfiber implants delivering paclitaxel for post-surgical chemotherapy against malignant glioma. Biomaterials 2008, 29, 2996-3003. [CrossRef] [PubMed]

7. López, J.E.O.; Jacoby, W.A. Microfibrous mesh coated with titanium dioxide: A self-sterilizing, self-cleaning filter. J. Air Waste Manag. Assoc. 2002, 52, 1206-1213. [CrossRef] [PubMed]

8. Obvintseva, L.; Dmitrieva, M.; Klimuk, A.; Shepelev, A.; Kozlova, N.; Sadovskaya, N.; Tomashpol'skii, Y.A.; Avetisov, A. Action of ozone on polysulfone-based microfibrous filters. Russ. J. Appl. Chem. 2010, 83, 1069-1073. [CrossRef]

9. Li, Z.-M.; Yang, M.-B.; Lu, A.; Feng, J.-M.; Huang, R. Tensile properties of poly(ethylene terephthalate) and polyethylene in-situ microfiber reinforced composite formed via slit die extrusion and hot-stretching. Mater. Lett. 2002, 56, 756-762.

10. Ha, S.-W.; Tonelli, A.E.; Hudson, S.M. Structural studies of Bombyx mori silk fibroin during regeneration from solutions and wet fiber spinning. Biomacromolecules 2005, 6, 1722-1731. [CrossRef] [PubMed]

11. Okuzaki, H.; Harashina, Y.; Yan, H. Highly conductive PEDOT/PSS microfibers fabricated by wet-spinning and dip-treatment in ethylene glycol. Eur. Polym. J. 2009, 45, 256-261. [CrossRef]

12. Wei, W.; Zhang, Y.; Zhao, Y.; Luo, J.; Shao, H.; Hu, X. Bio-inspired capillary dry spinning of regenerated silk fibroin aqueous solution. Mater. Sci. Eng. C Mater. Biol. Appl. 2011, 31, 1602-1608. [CrossRef]

13. Xu, X.; Uddin, A.J.; Aoki, K.; Gotoh, Y.; Saito, T.; Yumura, M. Fabrication of high strength PVA/SWCNT composite fibers by gel spinning. Carbon 2010, 48, 1977-1984. [CrossRef]

14. Lovett, M.L.; Cannizzaro, C.M.; Vunjak-Novakovic, G.; Kaplan, D.L. Gel spinning of silk tubes for tissue engineering. Biomaterials 2008, 29, 4650-4657. [CrossRef] [PubMed]

15. Jung, J.-H.; Choi, C.-H.; Chung, S.; Chung, Y.-M.; Lee, C.-S. Microfluidic synthesis of a cell adhesive Janus polyurethane microfiber. Lab Chip 2009, 9, 2596-2602. [CrossRef] [PubMed]

16. Lee, K.H.; Shin, S.J.; Kim, C.B.; Kim, J.K.; Cho, Y.W.; Chung, B.G.; Lee, S.-H. Microfluidic synthesis of pure chitosan microfibers for bio-artificial liver chip. Lab Chip 2010, 10, 1328-1334. [CrossRef] [PubMed]

17. Wei, C.; Dong, J. Direct fabrication of high-resolution three-dimensional polymeric scaffolds using electrohydrodynamic hot jet plotting. J. Micromech. Microeng. 2013, 23. [CrossRef]

18. Li, Z.M.; Yang, W.; Li, L.B.; Xie, B.H.; Huang, R.; Yang, M.B. Morphology and nonisothermal crystallization of in situ microfibrillar poly(ethylene terephthalate)/polypropylene blend fabricated through slit-extrusion, hot-stretch quenching. J. Polym. Sci. Pt. B Polym. Phys. 2004, 42, 374-385. [CrossRef]

19. Fridrikh, S.V.; Yu, J.H.; Brenner, M.P.; Rutledge, G.C. Controlling the fiber diameter during electrospinning. Phys. Rev. Lett. 2003, 90, 144502. [CrossRef] [PubMed]

20. McKee, M.G.; Wilkes, G.L.; Colby, R.H.; Long, T.E. Correlations of solution rheology with electrospun fiber formation of linear and branched polyesters. Macromolecules 2004, 37, 1760-1767. [CrossRef]

21. Shin, Y.; Hohman, M.; Brenner, M.; Rutledge, G. Experimental characterization of electrospinning: The electrically forced jet and instabilities. Polymer 2001, 42, 09955-09967. [CrossRef]

22. Katta, P.; Alessandro, M.; Ramsier, R.; Chase, G. Continuous electrospinning of aligned polymer nanofibers onto a wire drum collector. Nano Lett. 2004, 4, 2215-2218. [CrossRef]

23. Zhang, D.; Chang, J. Patterning of electrospun fibers using electroconductive templates. Adv. Mater. 2007, 19, 3664-3667. [CrossRef]

24. Cho, S.J.; Kim, B.; An, T.; Lim, G. Replicable multilayered nanofibrous patterns on a flexible film. Langmuir 2010, 26, 14395-14399. [CrossRef] [PubMed]

25. Yan, G.; Yu, J.; Qiu, Y.; Yi, X.; Lu, J.; Zhou, X.; Bai, X. Self-assembly of electrospun polymer nanofibers: A general phenomenon generating honeycomb-patterned nanofibrous structures. Langmuir 2011, 27, 4285-4289. [CrossRef] [PubMed]

26. Carlberg, B.; Wang, T.; Liu, J. Direct photolithographic patterning of electrospun films for defined nanofibrillar microarchitectures. Langmuir 2010, 26, 2235-2239. [CrossRef] [PubMed]

27. Dalton, P.D.; Joergensen, N.T.; Groll, J.; Moeller, M. Patterned melt electrospun substrates for tissue engineering. Biomed. Mater. 2008, 3. [CrossRef] [PubMed]

28. Bellan, L.M.; Craighead, H. Control of an electrospinning jet using electric focusing and jet-steering fields. J. Vac. Sci. Technol. B 2006, 24, 3179-3183. [CrossRef] 
29. Lee, J.; Lee, S.Y.; Jang, J.; Jeong, Y.H.; Cho, D.-W. Fabrication of patterned nanofibrous mats using direct-write electrospinning. Langmuir 2012, 28, 7267-7275. [CrossRef] [PubMed]

30. Ramakrishna, S.; Fujihara, K.; Teo, W.-E.; Lim, T.-C.; Ma, Z. An Introduction to Electrospinning and Nanofibers; World Scientific Pub Co. Inc: Singapore, 2005.

31. Katz, M.J.; George, E.B. Fractals and the analysis of growth paths. Bull. Math. Biol. 1985, 47, $273-286$. [CrossRef] [PubMed]

32. Mandelbrot, B.B.; Blumen, A. Fractal geometry: What is it, and what does it do? [and discussion]. Proc. R. Soc. Lond. A. 1989, 423, 3-16. [CrossRef]

33. Fractalyse-Fractal Analysis Software. Available online: http://www.fractalyse.org/ (accessed on 28 January 2016).

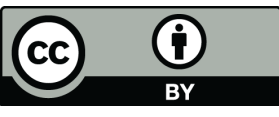

(C) 2016 by the authors; licensee MDPI, Basel, Switzerland. This article is an open access article distributed under the terms and conditions of the Creative Commons by Attribution (CC-BY) license (http:/ / creativecommons.org/licenses/by/4.0/). 